\title{
The English Ethnopsychological Personhood Construct Mind "Deconstructed" in Universally Intelligible Words
}

\author{
Bert Peeters $^{1,2 *}$
}

Received: 03 December 2018

Accepted: 29 January 2019

Published online: XXXX

(C) The Author(s) XXXX

\begin{abstract}
The dominance of English as the international lingua franca has led to rampant Anglocentrism and the reification of concepts that are in fact culturespecific. One such concept, often thought to refer to a universal human "attribute," is the ethnopsychological personhood construct mind. In this paper, I argue that the best weapon to combat Anglocentrism is the English language itself - or rather, a metalanguage based on what English shares with all other languages of the world. That metalanguage, which has existed for some time, is known as the "Natural Semantic Metalanguage (NSM)". This paper shows how far NSM practitioners have come in their efforts to demonstrate that the word mind is a cultural construct that has nothing universal about it and that cannot be used to define the ethnopsychological personhood constructs of other languages. Instead, it is just as culture-specific as any other ethnopsychological personhood construct and does not deserve any special status.
\end{abstract}

Keywords English · Mind - Ethnopsychological personhood constructs · Natural Semantic Metalanguage

Bu Bert Peeters

School of Literature, Languages and Linguistics, Australian National University, Canberra, ACT

2601, Australia

Bert Peeters

Griffith University, Brisbane, Australia

Bert Peeters

Universiteit of Antwerpen, Antwerpen, Belgium

* $\quad$ PO Box 898, Belconnen, ACT 2616, Australia 


\section{Introduction}

On May 17, 2005, Saudi Arabia's first English-language newspaper Arab News published an article titled "Lingua franca or cultural intruder?" in which English teacher Seenath Sajith, a resident from Jeddah, the second largest city in the country (after the capital Riyadh) and the country's commercial capital, wrote about the fear of many local parents that "learning a foreign language, especially English, will damage the culture they and their children belong to." She went on to say that, for these parents, "English is a wolf in sheep's clothing that may entice their children into modern lifestyles and ultimately help them land in trouble."1

The centuries-old image of a wolf in sheep's clothing is one we all know. Its origins are to be found in Ancient Greek, more specifically in one of the fables of the Greek story teller Aesop, who lived some 2,600 years ago. From there, it made its way into New Testament Greek (Gospel of Matthew, 7:15) and into many languages into which the Christian Bible was eventually translated, including English (for more detail, see Piirainen 2012: 277-282). Although no comparable image appears in the Quran or the Hadith (Habib 2017, personal communication), the metaphor is well known in the Islamic world as well, due to English having become the lingua franca of the planet, a fact duly underscored by Seenath Sajith, for whom English "acts as a lingua franca, a bridge that connects different nations and cultures."

In some ways, the fears of the parents quoted in Sajith's article are perhaps not entirely unfounded. I will demonstrate this in Section 3 of this paper, with reference to the English word mind, described in Section 2 as a so-called "ethnopsychological personhood construct." However, there is no reason to despair. In Section 4.1, I explain that the potentially damaging effects English can have can be undone by means of the very medium that inflicted it (i.e., English) — or rather, by means of a metalanguage based on what English shares with all other languages of the world. That metalanguage is no longer to be invented; it has existed for some time and is known by the abbreviation NSM ("Natural Semantic Metalanguage"). All we need is more people to join the practitioners of the "NSM approach" in their venture to describe culture-specific words (such as mind) in words that are universally intelligible. In Sections 4.2 and 4.3, I show how far NSM practitioners have come in their efforts to demonstrate that the word mind, often thought to refer to a universal human "attribute," is a cultural construct that has nothing universal about it and that cannot be used to define the ethnopsychological personhood constructs of other languages. Instead, it is just as culture-specific as any other ethnopsychological personhood construct and does not deserve any special status.

\section{Ethnopsychology and personhood}

\subsection{Ethnopsychological words and constructs}

Words like mind, heart, soul, and spirit that are part of the psychological vocabulary of a language are generally speaking unique to that language, even though, semantically

\footnotetext{
${ }^{1}$ Retrieved November 27, 2018, from http://www.arabnews.com/node/267051
} 
speaking, they may be closely related to similar-sounding words in neighboring languages. We might call them, for that very reason, "ethnopsychological words"and the constructs they name are "ethnopsychological constructs."

In the published transcript of a lecture delivered at the end of 2016 at an international forum on cognitive linguistics in Beijing, the Australian linguist Cliff Goddard (2018: 168) described ethnopsychological words as follows:

Words that we call ethnopsychological are basically words for parts of a person: not the physical body but the inside. In English, we have the word mind, it is a very English-specific word actually. Russian does not have a word for "mind," not really, but Russian has its word $d u s ̌ a$, a very famous word [that means] something like "soul.” [...] Chinese has xīn 心, Japanese kokoro, Korean maum. These words are not equivalent to one another.

Mind is arguably the English language's most salient ethnopsychological word, and the most important non-physical part of a person, at least from an Anglo point of view, ${ }^{2}$ followed by heart, spirit, and soul - though not necessarily in that order. $D u \check{s} a$ is probably just as salient for the Russians, xin for the Chinese, kokoro for the Japanese, and maum for the Koreans-but that does not make them identical, as Goddard rightly stresses. They are in fact different, very different.

Anthropologists, on the other hand, do not talk about ethnopsychological words but about ethnopsychological categories or constructs, which of course are the categories or constructs behind the words. The terms have been around for a while; one linguist who, over the course of her readings of the work of several anthropologists of the 1980s, came across the terms and has since adopted them in her own publications is Goddard's colleague and close collaborator, Anna Wierzbicka, whose nametogether with Goddard's - is synonymous with the "Natural Semantic Metalanguage approach," usually abridged to "NSM" or "NSM approach" (in this paper, to distinguish the metalanguage from the approach that takes its name, we will use compounds such as the latter; for details, see Section 4 below). Wierzbicka (1989) may well be the first paper by a linguist to use the term ethnopsychological category, which the author appears to have borrowed from Schieffelin (1985). Several other scholars are also mentioned, but it is a footnote of Schieffelin's that is actually quoted (Wierzbicka 1989: 46). ${ }^{3}$ In it, he draws attention to "the problem of the reification of essentially Western ethnopsychological categories that are then taken as the conceptual foundation of scientific inquiry" (Schieffelin 1985: 127). The expanded 1992 version of Wierzbicka's paper also refers to "ethnopsychological categories and constructs"; this is probably where, as far as the NSM approach is concerned, the origins of the term ethnopsychological construct lie.

From Wierzbicka's writings, the term ethnopsychological construct spread into other NSM literature, where it has been used by several authors turning their attention

\footnotetext{
${ }^{2}$ Goddard (2008: 94) describes it as "a concept that is semantically complex and exquisitely culture-bound."

${ }^{3}$ The reference provided by Wierzbicka is incorrect: two 1985 papers by Schieffelin appear to have been mixed up.
} 
to mind-, heart-, and soul-like words in a host of other languages [see Appendix 1A in Peeters (2019)]. Ethnopsychological construct is now an established term in NSM circles-much more so than ethnopsychological word, ethnopsychological concept, ethnopsychological entity, or ethnopsychological term, none of which are as commonly used. They are all interchangeable, though. In Goddard's (2015: 387) definition, for instance, ethnopsychological constructs are "nominal expressions [emphasis added, B.P.] designating non-physical parts of a person, akin to English mind, heart, soul, and spirit." Defining a construct as a nominal expression is tantamount to blurring the boundaries between word and concept, which is not always good practice; however, it does not matter much here since the focus is not so much on form as it is on meaning.

Strangely enough, among linguists, only NSM practitioners, as they have come to call themselves, ${ }^{4}$ seem to be using the term ethnopsychological construct. Nowhere is this more obvious than in Sharifian et al. (2008), a watershed volume on ethnopsychological constructs approached from a linguistic point of view, in which the subset of authors using the NSM approach (Goddard 2008; Yoon 2008) corresponds rigorously to the subset of authors using the term ethnopsychological construct.

\subsection{Personhood constructs}

Another term has found favor in NSM circles, and particularly in the latest writings of Danish linguist Carsten Levisen. Levisen speaks about personhood constructs, a term that clearly corresponds to the ethnopsychological constructs of other NSM authors. Indeed, for Levisen (2017: 123), personhood is a "terminological shortcut for semantic concepts in natural languages which meet the following criteria: they all conceptualize (or reify) something and this something is a part of a person, but which cannot be seen by people, and often stands in contrast to the body." Thus, in a co-authored paper (Levisen and Jogie 2015: 169), he investigates the "personhood construct mind in Trinidadian creole" and refers to some recent studies on "Japanese, Malay, Korean, and Thai personhood constructs" that have "further questioned the Anglophone stronghold of "the mind" (Levisen and Jogie 2015: 170); Levisen (2017), on the other hand, deals with personhood constructs in the author's own language, Danish.

The term personhood enjoys a certain popularity among philosophers (Torchia 2007; Palmquist 2010) and those who straddle the boundary between psychology and philosophy (Scott 1990; Harré 1998), but it is not clear who has been Levisen's primary source of inspiration. What is clear, though, is that personhood constructs, like ethnopsychological constructs, are cultural, linguistic, and conceptual in nature (Levisen 2017: 120-121).

\footnotetext{
${ }^{4}$ See, for instance, Ameka and Breedveld (2004: 173), Peeters (2007: 90), Levisen (2012: 233), Ye (2017: 17), and Wierzbicka (2018: 29).
} 


\subsection{Ethnopsychological personhood constructs}

The editor of and contributors to a recently published volume titled Heart-and soullike constructs across languages, cultures, and epochs (Peeters 2019) do not, for a number of reasons, speak of either "ethnopsychological constructs" (or "categories"), or "personhood constructs." Instead, they refer to "ethnopsychological personhood constructs (EPCs)," so as to have a foot in each camp. The term ethnopsychological is retained in acknowledgement of the work done in this area by ethnopsychologists such as Dorothy Holland, Catherine Lutz, Michelle Rosaldo, Edward Schieffelin, Geoffrey White, to name but a few. With the term personhood, they want to salute the work carried out within the NSM approach by Carsten Levisen, who prefers that term to the term ethnopsychological. At the same time, they want to clarify that emotions, for instance, which on the face of it also qualify as "ethnopsychological constructs," are not their main focus (even though it is impossible to talk about personhood constructs without at the same time touching on culturally specific emotions). Finally, they want to refer to constructs, because, although it may seem like a minor terminological distraction, that term is arguably doing a better job than the term category at highlighting culture-specificity, something the prefix ethno- is supposed to emphasize as well.

\section{Reification and anglocentrism}

If words such as mind, duša, xīn, kokoro, and maum, to limit ourselves to the examples in Goddard's (2018) definition of ethnopsychological words, are so different, how can we make sense of them? How do we describe the ways in which they differ and what they have in common?

For many in today's day and age, these questions do not arise anymore (if they ever did). The dominance of English as the international lingua franca (see Section 1) has led them to the assumption that all humans have hearts and minds. We may not all have souls and those who "question the ontological status of "the soul" (Levisen and Jogie 2015: 169) may even conclude that no one does, but the word mind in particular is taken for granted: Anglo scholars "pan-humanize the underlying concept and talk about it as if it existed per se, roaming in a non-linguistic, a-cultural space" (Levisen and Jogie 2015: 169-170). They "publish on 'how the mind works', on 'the mind and the brain', on 'body and mind', etc., as if 'the mind' was an obvious and apparently natural feature of the human setup" (Levisen and Jogie 2015: 170; Levisen in press). And it gets worse. Not only are humans presumed to have minds; animals - or at least certain animals - are as well. According to the publisher's blurb for Hayes (2018), "at birth, the minds of human babies are only subtly different from the minds of newborn chimpanzees." How would we know? Who has ever seen or touched the mind of a human baby? Who has ever seen or touched the mind of a newborn chimpanzee? Who can tell once and for all that all human babies and all newborn chimpanzees even have a mind? The reality is that not all of them do. The mind is not something out there that lends itself to direct observation. It is a construct of present-day English. To ignore this - as many do, even though they may think they are culturally aware - is equivalent 
to turning a blind eye to cultural diversity. And what if the Danes, for instance, started reifying their sind? How would Anglo scholars react? Levisen (2012: 75), himself a Dane, offered a sobering assessment:

The claim that speakers of all languages have a sind (with all its peculiar ethnopsychological implications) would obviously be blatantly Danocentric, but so is Anglophone linguists' and psychologists' talk about "the human mind," as if the English concept corresponds to objective reality whether or not speakers of other languages share the concept with speakers of English.

Of course, not everyone is as blind to cultural diversity as the individuals referred to above. However, the vast majority of scholars do uncritically rely on the tools provided by their own language or by the language they use in their writing, which is more often than not the English language. In other words, those of us who are conscious of cultural differences may nonetheless form the view that English words such as heart, soul, and mind can be used, without the slightest danger, to talk about the EPCs of other languages and other cultures, no matter how different they are. Three decades ago, Wierzbicka (1989: 46, revised as 1992: 40) cautioned against this approach as follows, again with reference to the English word mind:

The idea that mind is a folk concept reflected in the English language rather than an objective and universally valid category of human thought may seem surprising, if not impertinent. It is relatively easy to see that concepts such as those encoded in the Japanese words kokoro or ki [...], in the Samoan word loto [...], or in the Ilongot word rinawa [...] are culture-specific. It is harder to realize, however, that the same applies to the concept encoded in the English word mind.

The same point has since been reiterated on numerous occasions, either by Wierzbicka herself or by others. Some people have started listening, many more have not; the message still bears repeating. Large numbers of scholarly publications remain oblivious to the danger involved in taking English constructs such as the heart and the mind as universally shared yardsticks. Their authors seem to be utterly convinced that the use of English words and concepts to get to the bottom of words and concepts such as xin in Chinese, hati in Indonesian and Malay, and del in Persian, to add a few more to the list, is entirely unproblematic. Little has changed since, ten years ago, Goddard (2008: 79) noted that "with a few exceptions, even those scholars who are aware of the language-specific character of the 'mind concept' [...] seem convinced that the implicit Anglocentrism is benign." But is it really? Can we use the cultural constructs of one language, no matter how prevalent it is, to deconstruct those of another? Such deconstructions may look convincing to those who are fully conversant with the cultural constructs relied on. To others, in particular those whose cultural constructs are being deconstructed in this way, they are likely not to mean anything at all. For native speakers of English, it may be hard to imagine what is wrong with descriptions of $d u \check{s} a$ in terms of "the Russian soul," to give but one 
example. Readers in this category are invited to pause for a few seconds and ponder how they would feel about descriptions of soul as "the English duša." They do seem to lack cognitive plausibility, as do indeed the aforementioned descriptions of $d u s ̌ a$ in terms of "the Russian soul." We cannot use words like mind and soul to capture authentic "insider perspectives" on EPCs (or any other concepts, for that matter) in other languages.

Many will argue that this places us in an impossible bind. No matter how hard we try, we are always going to be bound by the limitations placed upon us by the language in which we think. Or are we?

\section{The Natural Semantic Metalanguage approach}

The truth of the matter is that we do not need to remain "imprisoned in English" (Wierzbicka 2014). "Wierzbicka's prison metaphor implies that the possibility of escape exists - as it does from any other prison - but that this requires conscious effort, creativity, and planning" (Levisen in press: 3 ). The alternative is known as the "NSM approach" and is presented in more detail in this section [for a recent, significantly more ambitious overview, see Goddard (2018)].

\subsection{Primes and explications}

The NSM is a powerful descriptive tool consisting of a maximally culture-neutral vocabulary and syntax developed over the last several decades by Anna Wierzbicka and Cliff Goddard, who, apart from relying on their own investigations, have been able to put to the best possible use the painstaking research carried out by linguists in Australia and elsewhere on dozens of typologically and genetically unrelated languages from all corners of the world. The NSM approach, which is inspired by a desire to overcome ethnocentrism and in particular Anglo bias in linguistic analysis, is the paradigm in linguistic semantics that uses NSM in its endeavor to explicate (i.e., make explicit) the meaning of culture-specific words and phrases using a technique known as "reductive paraphrasing." This technique aims at reducing and ultimately removing cultural complexity by re-paraphrasing it into semantically simple terms. The result is referred to as an explication, which is a fine-grained and, above all, non-Anglo-based description that the English language as such is woefully inadequate to emulate in ways that are convincing to native speakers of other languages. Written in non-technical language, they are accessible to cultural insiders (those for whom English is their native language) and cultural outsiders (all others) alike. The NSM approach has been illustrated in hundreds of publications, details of which are available at https://nsm-approach.net, a fully searchable and continually updated online database of relevant bibliographic notices.

NSM vocabulary is in essence limited to 65 so-called semantic primes. The list is now considered near-final. The primes are concepts or building blocks that are found in all (or nearly all) of the world's languages and that NSM practitioners believe to be semantically irreducible. They have resisted all attempts at semantic 
decomposition into more basic elements and are, therefore, deemed indefinable in terms that are semantically simpler than the primes themselves. NSM syntax is as universal as the primes, it is empirically validated, and it sets the rules for the combination of primes into the semantic components that make up an explication. Each of the primes has its own set of combinatorial properties. Since, until compelling evidence to the contrary (or unless stated otherwise), nothing in an explication is non-universal, explications can be translated without deformation or bias into other languages (other NSMs), thereby making culturally-specific terms universally intelligible.

The English and Arabic exponents of the primes, grouped into meaningful categories, are listed in Appendix 1. Comparable tables for many other languages, as well as charts that summarize the combinatorial properties of the various primes, can be found on the NSM homepage at http://bit.ly/1XUoRRV

\subsection{Explicating the English word mind in NSM}

Semantic explications are usually the result of a lot of hard work. Many get revised and amended over time. A particularly good example of this is provided by the EPC at the center of this paper, namely, the English word mind. Its "NSM history" spans no less than three decades (1989-2017) and provides an insight into the growth of the NSM approach as a whole. I will not say everything that could possibly be said about the primes and the grammar used in successive explications of the word mind. Instead, I will focus on the differences from one stage to the next.

A first attempt at explicating mind (Wierzbicka 1989: 49) is reproduced in explication $[\mathrm{A}] .^{5}$

\section{[A]}

(a) one of the two parts of a person

(b) one cannot see it

(c) because of this part, a person can think and know

Explication [A] depicts the mind as the invisible counterpart to the body, which is not mentioned (for reasons that will become clear); it is the part that enables us to acquire knowledge and to engage in all sorts of intellectual processes. However, instead of the kind of technical jargon exemplified in this paragraph, the explication uses words that are cross-translatable and universally intelligible: cannot see instead of invisible, because of instead of enable, think instead of engage in intellectual processes, know instead of acquire knowledge. The explication was slightly revised 3 years later (Wierzbicka 1992: 45):

\footnotetext{
${ }^{5}$ The bracketed letters preceding the components in all of the explications, except explications $[\mathrm{H}]$ and [J], are absent from the source documents. They have been added for easier cross-reference in the comments that follow.
} 
[B] mind

(a) one of two parts of a person

(b) one cannot see it

(c) because of this part, a person can think and know

A caption was added (the use of captions was not standard from the beginning), and the definite article in component (a) has gone missing ("one of the two parts" > "one of two parts"). The removal of the article is not as inconsequential as it looks: it reflects the idea that the mind is thought of as complementary to the body, without ruling out other dichotomies such as "body and soul." The definite article in explication [A] precluded that possibility.

Explication [C] (Goddard and Wierzbicka 1995: 46) has an expanded component (b):

[C] mind

(a) one of two parts of a person

(b) people cannot see it; people cannot touch it

(c) because of this part, a person can think

(d) because of this part, a person can know things

The reference to people's inability to touch the mind is a one-off. The new prime PEOPLE is used in component (b) instead of the pronoun one. This is an improvement since "one" in "one cannot see it" (explications [A] and [B]) is not an instance of the prime ONE, which is used in component (a). Thinking and knowing are separated out over two components, to avoid the use of "and", which is not a prime either. A direct object, "things," is added in component (d), but not in component (c).

For the next attempt, we have to wait until the mid-2000s (Wierzbicka 2005: 270):

[D] The English “mind”

(a) one of two parts of a person

(b) people cannot see this part

(c) because of this part, a person can think about things

(d) because of this part, a person can know things

The "it" in component (b) is replaced with an explicit noun phrase ("this part"), referring to the numeral "one" in component (a). The reference to untouchability is removed. "Think" in component (c) now also gets a complement, which is prepositional ("about things").

Explications [E], [F], and [G] are all Goddard's. They are explicitly based on Wierzbicka's earlier work. Explication [E] is from Goddard (2007: 25). 


\section{[E] mind (a person's mind)}

(a) one of two parts of someone (one part is the body, this is the other part)

(b) people cannot see this part

(c) because someone has this part, this someone can think about things

(d) because someone has this part, this someone can know things

(e) when someone thinks about something, something happens in this part

Several important differences exist between explications [D] and [E]. The change from "a person" to "someone" in component (a) follows the dismissal of the former as a so-called allolex of the prime sOMEONE. Allolexes are word forms that express a single meaning in complementary contexts. They are an important feature in the NSM lexicon that can be further exemplified by means of the complementarity between I and ME, or between THIS and THESE, etc. From now on, the prime retains only one form, which is used even in contexts where the former allolex was the preferred option until now (e.g., after a determiner: THIS PERSON > THIS SOMEONE). The change reflects the realization that the word person refers to a concept that is not semantically simple and introduces unnecessary culture-specificity into the explication. Its presence in the caption is tolerated.

Still in component (a), the identity of the two "parts of someone" is further specified. Never before had the prime BODY made its appearance in explications of the word mind. The English word body has different meanings in the phrases body and mind and the head and the body (roughly, BODY without the head). The meaning associated with the prime is that of the former of the two phrases. Goddard and Peeters (2006: 18) point out that BODY was elevated to prime status (and, therefore, no longer deemed to be decomposable) in Goddard (2001), but it is in fact already mentioned in earlier work: in Wierzbicka (1998), it appears for the first time in a table of primes and is used in a few semantic explications. ${ }^{6}$ No compelling evidence has been found since that time that questions the status of BODY as a semantic prime (Wierzbicka 2014: 40-51).

The "because of" formulation in components (c) and (d) of explication [D] is replaced with a full-fledged clause ("because someone has this part"). Component (e) is new. It is a reference to the dynamic aspect of the mind concept, for which there exists linguistic evidence (cf. expressions such as What's going on in his mind? or phrases such as the workings of the mind).

Between explications [E] and [F] (Goddard 2008: 79), the changes are minimal. The caption expands, triggering a change in component (a), where the prime THIS is added in front of the prime SOMEONE.

\footnotetext{
${ }^{6}$ In some ways, these explications are reminiscent of formulations in Wierzbicka (1988) and in the work it is based on, but in that earlier work "body" was still considered to be a "near-primitive" (Wierzbicka 1985: 9) at best: it was thought to be semantically complex and therefore not a semantic prime in the true sense of the word. Its use in semantic explications was condoned for practical reasons. Wierzbicka's (1975: 509; 1980: 169-170) early work provides semantic explications of the English word body that have never been explicitly dismissed as inadequate but obviously are. They date from about the same period as Brown's (1976) and Andersen's (1978) useful surveys of body-part nomenclature, in which the meaning "body" is claimed to be universally lexicalized.
} 
[F] someone's mind (a person's mind)

(a) one of two parts of this someone (one part is the body, this is the other part)

(b) people cannot see this part

(c) because someone has this part, this someone can think about things

(d) because someone has this part, this someone can know things

(e) when someone thinks about something, something happens in this part

Explication [G] (Goddard 2010: 83) heralds a return to a simpler caption; this time, the phrase between brackets is removed. Note the use of "people" in components (c) and (d), as opposed to "someone" in explications [E] and [F]. The plural form will not be maintained after 2010 .

[G] someone's mind

(a) one of two parts of this someone (one part is the body, this is the other part)

(b) people cannot see this part

(c) because people have this part, people can think about things

(d) because people have this part, people can know things

(e) when someone thinks about something, something happens in this part

Levisen and Jogie (2015: 179) are the first to list components in clusters instead of one by one. Their explication is reproduced in explication [H].

\section{[H] Anglo English mind}

(a) something

this something is one of two parts of someone

one part is the body, this is the other part

people cannot see this part

(b) because someone has this part, this someone can think about many things at the same time, because someone has this part, this someone can know many things

(c) when someone thinks about something, something happens in this part

Someone does not appear in the caption, which means that no demonstrative appears with the prime SOMEONE in (mega)component (a). The old component (a) in explication $[\mathrm{G}]$ is pulled apart. For the first time, the mind is referred to as "something." The new (mega)component (a) (four lines) also refers to the mind's invisibility. The remaining three components of explication $[\mathrm{G}]$ are spread out over (mega)components (b) and (c). In component (b), the quantifier MANY is added as the trigger for the plural "things," which is an allolex of somETHING.

Wierzbicka (2016: 458) compares explication [I], which follows 1 year later, to her first attempts (explications [A] and [B]), noting that "in the course of the intervening two decades, both the lexicon and the syntax of the NSM have been perfected" but that the "references to two parts of a person and to thinking and knowing" have been preserved. 


\section{[I] someone's mind}

(a) something

(b) this something is part of this someone

(c) people cannot see this something

(d) this something is not part of this someone's body

(e) when this someone is thinking about something, something happens in this part

(f) because this someone has this part, it is like this:

(g) this someone can think many things about many things

(h) this someone can know many things about many things

The "reference to two parts of a person" is not as clear as Wierzbicka makes out, since component (b) could imply there are more than two parts to someone in any given conceptualization, not just the body and the mind. Another novelty is the assertion that, while the mind is part of someone (component b), it is not a body part (component d). The dynamic aspect gets promoted (i.e., moves higher up) and now precedes the references to thinking and knowing, which are grouped together in a subordinate scenario introduced by "it is like this" (rather than being linked together with "at the same time"). In addition, the thinking and knowing abilities are made syntactically equivalent: both verbs have a direct object and a prepositional complement, and the quantifier MANY is used to underscore that the mind is at the basis of a multitude of thoughts and knowledge.

Levisen (2017: 123) combines aspects of explications [H] and [I] and applies a "semantic template" specifically devised for EPCs (for more information, see Section 4.3). The template closely mirrors the (mega)components in explication $[\mathrm{H}]$. The result appears in explication $[\mathrm{J}]$ :

\section{[J] mind (someone's mind)}

(a) something GENERAL CONCEPTUAL STATUS this something is a part of this someone this part is not a part of the body people cannot see this part

(b) because someone has this part, it is like this:

CHARACTERISTICS this someone can think about things this someone can know things

(c) when someone thinks about something, DYNAMICS something happens in this part

This is how far NSM practitioners have come in their attempts at explicating the Anglo concept hiding behind the English word mind. It is more than conceivable, though, that we have not reached the end of the road and that, in light of new insights gained from the study of EPCs worldwide, more adjustments will need to be made as time goes by. One such adjustment may see the reintroduction of the quantifier MANY before the noun THINGS in component (b), which in its current format, all of a sudden, once again lacks a trigger for the use of the plural allolex of the prime sOMETHING. 


\subsection{Semantic templates}

I would like to conclude this section by saying one or two things about semantic templates. These have been proposed not only for EPCs, but also for several other lexical categories and for higher order categories, such as proverbs and metaphors. They provide a structure that captures shared aspects, thereby making comparison of explications both easier and more effective. The use of templates allows for a more focused comparison: it makes more sense to compare components in meaningful clusters than to go straight down to the smallest meaningful level, which is that of individual components.

Two templates have been proposed for EPCs so far. ${ }^{7}$ Ideally, there should be only one; time will tell which one is better. Templates, like explications, are experiments (cf. Section 4.2). Levisen's (2017) template has been exemplified in explication [J] above; it has a tripartite structure (General conceptual status, Characteristics, and Dynamics), which can be expanded. ${ }^{8}$ Levisen (2017: 126) explains, in NSM, what each of the three blocks is about. The first block answers the question "what it is"; the second, "what it is like"; the third, "what can happen because of this something," including "what can happen in this part," "what can happen to this part," "what it (sometimes) can be like," and "what it (sometimes) wants to do."

Wierzbicka's (2016) template consists of four blocks, with no suggestion that it can be expanded. Since it has not been applied to the English word mind, I will not present it in detail, except to say that, unlike Levisen's captions, Wierzbicka's are written in NSM, thus falling in line with the explication itself. The structure of Wierzbicka's template is as follows:

someone's [name of the explicated EPC]

\section{[A] [WHAT IT IS]}

$\cdots$

[B] [HOW THIS SOMEONE CAN THINK ABOUT THIS SOMETHING] $\cdots$

[C] [WHAT THIS PART OF SOMEONE IS LIKE]

$\cdots$

[D] [WHAT PEOPLE CAN KNOW ABOUT THIS PART OF SOMEONE]

The use of NSM in captions is an innovation worthy of further exploration. Most templates that have been proposed over the years, including Levisen's, have relatively short captions that are printed in small capitals on the right-hand side of the first line of the blocks they name. This typographical layout, which is now well established,

\footnotetext{
${ }^{7}$ The template used by Svetanant (2013) is based on unpublished proposals that eventually led to one of them. It is not included in the count.

${ }^{8}$ In some cases, a need exists for a Social valuation block that might contain statements such as "it is good if other people can know what happens in this part of someone" (Levisen 2017: 125) or "it is good if people can think with this part at all times" (Levisen 2017: 131).
} 
has the advantage of standing out and providing clear guidance to the overall structure of an explication as well as an indication of what each block contributes to the explication as a whole. This was another reason for the introduction of templates (in addition to their primary role of facilitating comparison, as explained above). Captioned templates are a useful device in the case of longer explications, which readers might otherwise find difficult to follow through to the end. They provide additional navigational help.

But, the established typographical layout comes at a price: the brevity required to enable them to be printed on the right-hand side of an explication makes it impossible to use NSM, and captions that are not in NSM may be counterproductive, as they go against the very spirit of NSM semantics. This is why, in recent work, Wierzbicka and one or two other authors rely on captions printed in big capitals at the top of their respective blocks, which goes against established practice but allows for the use of NSM, even in captions.

\section{Conclusion}

NSM has been used extensively to prove how a culture-neutral and languageindependent tool relying on a set of empirically grounded and universally applicable semantic primes, such as I, YOU, SAY, WANT, FEEL, THINK, KNOW, GOOD, and BAD, can help us see through the complex meanings of culture-specific concepts, such as "the English mind" and other EPCs, not only in English but also in other languages (see Peeters 2019 for more detail). Rather than a potential wolf in sheep's clothing, like the full-fledged version of English, NSM is a "sheep in wolf's clothing": it may look as dangerous as unadulterated English, but it is tame and innocent in comparison. Not only is it tame and innocent, but it is also extremely useful as a tool for cultureneutral linguistic description.

I claim no originality whatsoever for manipulating the well-known image of a wolf in sheep's clothing as I have done. As it turns out, the image is often manipulated in one of two ways. A simple inversion is at the basis of the phrase a sheep in wolf's clothing; alternatively, leaving one of the two animals out of the equation leads to the phrases a sheep in sheep's clothing and a wolf in wolf's clothing, which can also be used as labels for the English language. On one hand, English is a sheep in sheep's clothing, a language like any other. On the other hand, because of creeping "linguistic imperialism" (Phillipson 1992; 2010), it is often perceived as a threat to the survival of other languages, a wolf in wolf's clothing, not only for a sizeable number of endangered languages, but also — albeit to a lesser extent-for other mainstream languages including, as indicated above, Arabic.

Back to NSM. The metalanguage was not always what it is today; it has come a long way since its first incursions into the field of ethnopsychology. Some early primes have been abandoned, many more have been added. The combinatorial properties of primes have been clarified. New tools and concepts have been added to the NSM toolkit, such as allolexy and semantic templates (not an exhaustive list). Explications have been subjected to a constant process of further elaboration and fine-tuning (see Section 4.2 of this paper). For NSM practitioners, no explication is ever final—or, to 
put it differently, "every explication is an experiment" (Cliff Goddard). ${ }^{9}$ This applies to explications of the Anglo EPC mind as much as it does to any other explication. It is a healthy stance to take, and a clear sign that the NSM approach, as illustrated here, is alive and well and has a bright future ahead of itself.

Acknowledgements Sections 2-5 of this paper are based on Sections 1-3 of a chapter titled "Delving into heart- and soul-like constructs: Describing EPCs in NSM." Copyright (C) 2019 from Heart- and soullike constructs across languages, cultures and epochs, ed. by Bert Peeters. Reproduced by permission of Taylor and Francis Group, LLC, a division of Informa plc.

\section{References}

Ameka, F. K., \& Breedveld, A. (2004). Areal cultural scripts for social interaction in West African communities. Intercultural Pragmatics, 1(2), 167-187. doi: 10.1515/iprg.2004.1.2.167

Andersen, E. S. (1978). Lexical universals of body-part terminology. In J. H. Greenberg (Ed.), Universals of human language: word structure (Vol. 3, pp. 335-368). Stanford, CA: Stanford University Press.

Brown, C. H. (1976). General principles of human anatomical partonomy and speculations on the growth of partonomic nomenclature. American Ethnologist, 3(3), 400-424. doi: 10.1525/ae.1976.3.3.02a00020

Goddard, C. (2001). Lexico-semantic universals: a critical overview. Linguistic Typology, 5(1), 1-65. doi: 10.1515/lity.5.1.1

Goddard, C. (2007). A culture-neutral metalanguage for mental state concepts. In A. C. Schalley \& D. Khlentzos (Eds.), Mental states: language and cognitive structure (Vol. 2, pp. 11-34). Amsterdam, The Netherlands: John Benjamins. doi: 10.1075/slcs.93.04god

Goddard, C. (2008). Contrastive semantics and cultural psychology: English heart vs. Malay hati. In F. Sharifian, R. Dirven, N. Yu, \& S. Niemeier (Eds.), Culture, body, and language: conceptualizations of internal body organs across cultures and languages (pp. 75-102). Berlin, Germany: Mouton de Gruyter. doi: 10.1515/9783110199109.2.75

Goddard, C. (2010). Universals and variation in the lexicon of mental state concepts. In B. Malt \& P. Wolff (Eds.), Words and the mind: How words capture human experience (pp. 72-92). Oxford, UK: Oxford University Press. doi: 10.1093/acprof:oso/9780195311129.003.0005

Goddard, C. (2015). Words as carriers of cultural meaning. In J. R. Taylor (Ed.), The Oxford handbook of the word (pp. 380-398). Oxford, UK: Oxford University Press. doi: 10.1093/ oxfordhb/9780199641604.013.027

Goddard, C. (2018). Ten lectures on natural semantic metalanguage: exploring language, thought and culture using simple, translatable words. Leiden, The Netherlands: Brill. doi: 10.1163/9789004357723

Goddard, C., \& Peeters, B. (2006). The natural semantic metalanguage (NSM) approach: an overview with reference to the most important Romance languages. In B. Peeters (Ed.), Semantic primes and universal grammar: evidence from the Romance languages (pp. 13-38). Amsterdam, The Netherlands: John Benjamins. doi: 10.1075/slcs.81.07god

Goddard, C., \& Wierzbicka, A. (1995). Key words, culture and cognition. Philosophica, 55(1), $37-67$.

Habib, S. (2017). The meanings of 'angel' in English, Arabic, and Hebrew. In Z. Ye (Ed.), The semantics of nouns (pp. 89-119). Oxford, UK: Oxford University Press. doi: 10.1093/oso/9780198736721.003.0004

Harré, R. (1998). The singular self: an introduction to the psychology of personhood. London, UK: Sage.

Hayes, C. (2018). Cognitive gadgets: the cultural evolution of thinking. Cambridge, MA: Harvard University Press.

Levisen, C. (2012). Cultural semantics and social cognition: a case study on the Danish universe of meaning. Berlin, Germany: de Gruyter Mouton. doi: 10.1515/9783110294651

Levisen, C. (2017). Personhood constructs in language and thought: new evidence from Danish. In Z. Ye (Ed.), The semantics of nouns (pp. 120-146). Oxford, UK: Oxford University Press. doi: 10.1093/ oso/9780198736721.003.0005

\footnotetext{
${ }^{9}$ The phrase pops up at just about every NSM workshop, and in many NSM-inspired talks and seminars, but to the best of my knowledge, Goddard has never used it in print.
} 
Levisen, C. Biases we live by: Anglocentrism in linguistics and cognitive sciences. Language Sciences (in press). doi: 10.1016/j.langsci.2018.05.010

Levisen, C., \& Jogie, M. R. (2015). The Trinidadian 'theory of mind': Personhood and postcolonial semantics. International Journal of Language and Culture, 2(2), 169-193. doi: 10.1075/ijolc.2.2.02lev

Palmquist, S. R. (Ed.). (2010). Cultivating personhood: Kant and Asian philosophy. Berlin, Germany: de Gruyter.

Peeters, B. (2007). Australian perceptions of the weekend: evidence from collocations and elsewhere. In P. Skandera (Ed.), Phraseology and culture in English (pp. 79-107). Berlin, Germany: Mouton de Gruyter. doi: 10.1515/9783110197860.79

Peeters, B. (Ed.). (2019). Heart- and soul-like constructs across languages, cultures and epochs. New York, NY: Routledge.

Phillipson, R. (1992). Linguistic imperialism. Oxford, UK: Oxford University Press.

Phillipson, R. (2010). Linguistic imperialism continued. New York, NY: Routledge.

Piirainen, E. (2012). Widespread idioms in Europe and beyond: toward a lexicon of common figurative units. New York, NY: Peter Lang. doi: 10.3726/978-1-4539-0845-7

Schieffelin, E. (1985). The cultural analysis of depressive affect: an example from New Guinea. In A. Kleinman \& B. Good (Eds.), Culture and depression: studies in the anthropology and cross-cultural psychiatry of affect and disorder (pp. 101-133). Berkeley: University of California Press.

Scott, G. E. (1990). Moral personhood: an essay in the philosophy of moral psychology. Albany NY: SUNY Press.

Sharifian, F., Dirven, R., Yu, N., \& Niemeier, S. (Eds.). (2008). Culture, body, and language: conceptualizations of internal body organs across cultures and languages. Berlin, Germany: Mouton de Gruyter. doi:10.1515/9783110199109

Torchia, J. (2007). Exploring personhood: an introduction to the philosophy of human nature. Lanham, MD: Rowman \& Littlefield.

Wierzbicka, A. (1975). Why "kill" does not mean "cause to die": the semantics of action sentences. Foundations of Language, 13(4), 491-528.

Wierzbicka, A. (1980). Lingua mentalis: the semantics of natural language. Sydney, Australia: Academic Press.

Wierzbicka, A. (1985). Lexicography and conceptual analysis. Ann Arbor, MI: Karoma.

Wierzbicka, A. (1988). The semantics of grammar. Amsterdam, The Netherlands: John Benjamins. doi: $10.1075 /$ slcs. 18

Wierzbicka, A. (1989). Soul and mind: Linguistic evidence for ethnopsychology and cultural history. American Anthropologist, 91(1), 41-58. doi: 10.1525/aa.1989.91.1.02a00030

Wierzbicka, A. (1992). Semantics, culture, and cognition: Universal human concepts in culture-specific configurations. Oxford, UK: Oxford University Press.

Wierzbicka, A. (1998). Russian emotional expression. Ethos, 26(4), 456-483. doi: 10.1525/ eth.1998.26.4.456

Wierzbicka, A. (2005). Empirical universals of language as a basis for the study of other human universals and as a tool for exploring cross-cultural differences. Ethos, 33(2), 256-291. doi: 10.1525/ eth.2005.33.2.256

Wierzbicka, A. (2014). Imprisoned in English: the hazards of English as a default language. New York, NY: Oxford University Press. doi: 10.1093/acprof:oso/9780199321490.001.0001

Wierzbicka, A. (2016). Two levels of verbal communication, universal and culture-specific. In A. Rocci \& L. de Saussure (Eds.), Verbal communication (pp. 447-482). Berlin, Germany: De Gruyter Mouton. doi: 10.1515/9783110255478-024

Wierzbicka, A. (2018). Speaking about God in universal words, thinking about God outside English. In P. Chilton \& M. Kopytowska (Eds.), Religion, language, and the human mind (pp. 19-51). Oxford, UK: Oxford University Press. doi: 10.1093/oso/9780190636647.003.0002

Ye, Z. (2017). The semantics of nouns: a cross-linguistic and cross-domain perspective. In Z. Ye (Ed.), The semantics of nouns (pp. 1-18). Oxford, UK: Oxford University Press. doi: 10.1093/ oso/9780198736721.003.0001

Yoon, K-J. (2008). The Korean conceptualization of heart: an indigenous perspective. In F. Sharifian, R. Dirven, N. Yu, \& S. Niemeier (Eds.), Culture, body, and language: conceptualizations of internal body organs across cultures and languages (pp. 213-243). Berlin, Germany: Mouton de Gruyter. doi: 10.1515/9783110199109.3.213 


\section{Appendix 1 Semantic primes (English and Arabic exponents, grouped into related categories; excerpted from Table 4.1 in Habib 2017: 92-93)}

\begin{tabular}{|c|c|c|}
\hline English exponents & Arabic exponents & Category \\
\hline $\begin{array}{l}\text { 1, YOU, SOMEONE, } \\
\text { SOMETHNG THING, } \\
\text { PEOPIE, BODY }\end{array}$ & $\begin{array}{l}\text { ANA, ANTA, AHUD, SHAY, NAS, } \\
\text { חISM }\end{array}$ & Substantives \\
\hline KNND, PART & NAW', rUZ' & $\begin{array}{l}\text { Relational } \\
\text { substantives }\end{array}$ \\
\hline $\begin{array}{l}\text { TuLs, TuE SAME, } \\
\text { OTHER }\end{array}$ & HADHA, NAFS, AKHAR & Determiners \\
\hline $\begin{array}{l}\text { ONG, TWO, } \\
\text { MUCH MANY, } \\
\text { LTTL } \sim F E \text {, SOME, } \\
\text { AII. }\end{array}$ & $\begin{array}{l}\text { WAHID, mnNAN, KATItR, QAIH, } \\
\text { BA'b, KUIL. }\end{array}$ & Quantifiers \\
\hline GOOD, BAD & JAYrID, sAYr' & Evaluators \\
\hline DSG, SMALI. & KABth, SAGHTR & Descriptors \\
\hline $\begin{array}{l}\text { THEx, KNOW, WANT, } \\
\text { DON'T WANT, FEI, } \\
\text { SE, HEAR }\end{array}$ & $\begin{array}{l}\text { YUFAKKER, YA'REF, YURTD, LA } \\
\text { YUSID, YASH'UR YAIUUSS, YARS, } \\
\text { YASMA }\end{array}$ & $\begin{array}{l}\text { Mental } \\
\text { predicates }\end{array}$ \\
\hline SAY, WORDS, TRUE & YAQCL, KAIIMAT, SAIth & Speech \\
\hline $\begin{array}{l}\text { DQ, HAPPEN, MOVE, } \\
\text { TOUCH }\end{array}$ & $\begin{array}{l}\text { YA'MAL YAF' AL, YAHDUTH, } \\
\text { YATAHARRAK, YAMUSS }\end{array}$ & $\begin{array}{l}\text { Actions, } \\
\text { events, } \\
\text { movement, \& } \\
\text { contact }\end{array}$ \\
\hline
\end{tabular}

\begin{tabular}{|c|c|c|}
\hline English exponents & Arabic exponents & Category \\
\hline 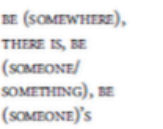 & 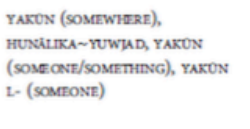 & $\begin{array}{l}\text { Location, } \\
\text { specification, } \\
\text { existence, \& } \\
\text { possession }\end{array}$ \\
\hline IIVE, DEI & YA'TS YAHYA, YAMOT & $\begin{array}{l}\text { Life and } \\
\text { death }\end{array}$ \\
\hline $\begin{array}{l}\text { WhEN TME, NOW, } \\
\text { BEPON, AFTR, A } \\
\text { LONG TME, A SHORT } \\
\text { TME, POR SCMER TME, } \\
\text { MOMENT }\end{array}$ & $\begin{array}{l}\text { DNDAMA MATA WAGT MARRA, } \\
\text { AL'AS, QAAR, BA'b, WAQT TAWTH, } \\
\text { WAQT QAStR, LAA'DE LWAQT, } \\
\text { LAIEA }\end{array}$ & Time \\
\hline $\begin{array}{l}\text { WHESE PLACE, HESE, } \\
\text { ABOVE, BELOW, FAR, } \\
\text { NEAR, SLDE, DSSIDE }\end{array}$ & 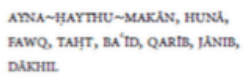 & Space \\
\hline $\begin{array}{l}\text { Not, sane, cas, } \\
\text { secatse, If }\end{array}$ & 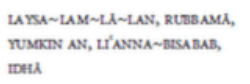 & $\begin{array}{l}\text { Logical } \\
\text { concepts }\end{array}$ \\
\hline VERY, MORE & IDDAN, ALMAZID & $\begin{array}{l}\text { Intensifier, } \\
\text { augmentor, }\end{array}$ \\
\hline LIKE AS WAY & мerrit. & Similarity \\
\hline
\end{tabular}

(Habib 2012bx Goddard and Wierabicka 2014) 